\title{
RADIATION-RELATED EYE DISEASES AMONG WELDERS OF SUAME ‘MAGAZINE' IN THE KUMASI METROPOLIS
}

\author{
D. B. Kumah, F. Cobbina, and D. J. Duodu, \\ Department of Optometry and Visual Science, \\ Kwame Nkrumah University of Science and Technology, Kumasi, Ghana
}

\begin{abstract}
The purpose of this study was to investigate the effects of radiations on the ocular health of welders and to determine the prevalence of ocular diseases among them in the Kumasi metropolis. In this study, 470 welders (test group) and 450 non-welders (control group) at Suame "Magazine" in the Kumasi metropolis were enrolled for the study. Methods employed in the examination were the administration of a questionnaire seeking clinical and ocular history, visual acuity measurements, external eye examination and ophthalmoscopy. Where necessary, referrals were written for patients to the Komfo Anokye Teaching Hospital (KATH) for further examination and treatment. Two hundred and forty two welders, (51.1\%) had worked for a period of over ten years. The chief ocular complaints found amongst the respondents were gritty sensation $(65.1 \%)$ and excessive tearing (56.0\%). The commonest radiation-related ocular diseases were pterygium (56.6\%), photoconjunctivitis $(22.6 \%)$ and cataract $(5.1 \%)$ whereas in the control group the commonest conditions were pterygium (6.2\%), pinguecula (2.2\%) and cataract (1.3\%). There was a small number of retinopathies associated with radiation (4.0\%). Most (60.0\%) of the welders used electricity (arc welding) and the remaining (40.0\%) used carbide (oxy-acetylene flame). A total of 308 (65.5\%) welders and 76 (16.9\%) non-welders (control group) had one or more ocular conditions. The prevalence of eye diseases among the welders and control group is thus $65.5 \%$ and $16.9 \%$ respectively. In conclusion, it was seen that the ocular symptoms and ailments prevalent among the welders were most likely due to the radiations they are exposed to in their work environment.
\end{abstract}

Keywords: Welders, radiation-related, pterygium, photoconjunctivitis, photokeratitis, cataract

\section{INTRODUCTION}

Everyone is exposed to UV radiation from the sun and an increasing number of people are exposed to artificial sources used in industry, commerce and recreation. Emissions from the sun include visible light, heat and UV radiation.
The UV region covers the wavelength range 100-400nm and is divided into three bands:

- $\quad$ UVA (315-400nm)

- UVB (280-315nm)

- $\quad$ UVC (100-280nm) 


\section{Kumah et al.}

As sunlight passes through the atmosphere, all UVC and approximately $90 \%$ of UVB radiation is absorbed by ozone layer, water vapour, oxygen and carbon dioxide of earth's atmosphere. UVA radiation is less affected by the atmosphere. Therefore, the UV radiation reaching the Earth's surface is largely composed of UVA with a small UVB component (WHO, 2010).

Welding arc emits a wide spectrum of radiations ranging between $200 \mathrm{~nm}-1400 \mathrm{~nm}$. These radiations include ultraviolet (UV) rays (200$400 \mathrm{~nm})$, visible light (400-700nm) and infrared rays $(700-1400 \mathrm{~nm})$. Ultraviolet radiation and far infra-red (IR) are absorbed by the cornea and lens whereas visible light and near infrared penetrate to the retina (Fich et al., 1993; Voke, 1999).

When given sufficient intensity and duration, the radiations will cause thermal or photochemical damage which may be permanent and sight threatening (Mainster et al., 1983). Retinal injuries resulting from exposure to welding arc radiation have been reported, (Uniat et al., 1986) but such injuries are uncommon.

Repeated exposure of the eyes to UV radiation (UVR) causes both short-term eye complaints and permanent eye damage. Short-term complaints include mild irritations such as excessive blinking, swelling or difficulty looking at strong light (Cains, 1992).

Exposure to UV radiation over long periods can result in more serious damage to the eyes, including cataracts, pterygium, solar keratopathy (cloudiness of the cornea), cancer of the conjunctiva and skin cancer of the eyelids and around the eyes (Taylor, 1981; Moran and Hollows, 1984; Hollows and Moran, 1981; West et al., 1989).

This study sought to determine the prevalence of radiation-related ocular diseases among welders in the Kumasi metropolis and to educate them on safety precautions to protect their vision.

\section{MATERIALS AND METHODS}

Study Population

In this population-based study, the subjects used comprised the welders, non-welding mechanics/artisans and dealers in automobile spare parts (as a control group) at the Suame 'Magazine' in the Kumasi Metropolis, the capital town of Ashanti region. Ashanti Region is one of the ten regions in Ghana with many welders, both in the construction and automobile industries. These welders are exposed to the welder's arc (lamp) which emits electromagnetic radiations (including infra-red, visible and ultraviolet rays) which are of great concern to the optometrist because of the injuries they can cause to the eye.

\section{Sampling}

Through purposive sampling, Suame SubMetropolis was selected, based on the fact that this area houses most of the garages in the $\mathrm{Ku}$ masi Metropolis and would be easily accessible. Through the executives of the Welders Association and mechanics as well as the dealers in spare parts, the members were invited to participate in the study after explaining the purpose of the study and the benefits they will derive from it. Informed consent forms were then signed by those who volunteered to participate and the dates for the examinations communicated to them. A total of 920 respondents comprising 470 welders and 450 non-welders (control group) were recruited for the study.

\section{Data Collection Technique}

The examination was done on the work premises of the artisans. The data collection tool employed was a self administered questionnaire. An interviewer read and explained the questionnaire in the local language to the respondents and then filled it based on their responses.

\section{Patient History}

For the enquiry into the patient's history, features considered included a review of the nature of the presenting problem, chief complaint, ocular and general health history, and family 
Radiation-related eye diseases among welders...

ocular history, use of medication and allergies experienced.

\section{Various Clinical Examinations}

The screening examination comprised the assessment of visual acuity using Snellen's visual acuity chart, which was recorded with and without distance spectacles. All the participants underwent torchlight examination under binocular loupe to assess external eye health and direct Ophthalmoscopy using Welch Allyn ophthalmoscope to assess the fundus. Axis deviation was assessed by cover/uncover test. The visual field was estimated in each eye by the confrontation method.

\section{Health Education}

The welders were educated on ocular health and the risk involved in their work and the use of appropriate protective devices at work.

\section{Statistical Method}

The Statistical Package for Social Scientists (SPSS) Version 15.0 software was employed in the data analysis. The chi square test was used to compare percentages. Differences were considered to be statistically significant at the 5\% level.

\section{RESULTS AND DISCUSSION}

A total number of 470 welders and 450 nonwelders were screened. Their ages ranged from 16 to 75 years. The modal age was 25 years. All the welders were male while $329(73.1 \%)$ men and 121 (26.9\%) women constituted the control group.

\section{Age Distribution and Years of Experience}

Table 1 displays the age characteristics of the respondents while Table 2 shows the years of experience of the welders. The study revealed that the older artisans had spent more years in the work. This indirectly meant that they had been exposed more to the radiations. It was revealed that $242(51.5 \%)$ welders had over ten years experience.
Table 1. Age distribution of the respondents

\begin{tabular}{lllll}
\hline $\begin{array}{l}\text { Age } \\
\text { range }\end{array}$ & Welders & Control & Total & $\begin{array}{l}\text { Per- } \\
\text { cent }\end{array}$ \\
\hline $16-20$ & 55 & 25 & 80 & 8.7 \\
$21-25$ & 88 & 73 & 161 & 17.5 \\
$26-30$ & 77 & 48 & 125 & 13.6 \\
$31-35$ & 46 & 39 & 85 & 9.2 \\
$36-40$ & 56 & 41 & 97 & 10.5 \\
$41-45$ & 46 & 34 & 80 & 8.7 \\
$46-50$ & 46 & 36 & 82 & 8.9 \\
$51-55$ & 27 & 50 & 77 & 8.4 \\
$56-60$ & 18 & 43 & 61 & 6.6 \\
$61-65$ & 6 & 30 & 36 & 3.9 \\
$66-70$ & 4 & 22 & 26 & 2.8 \\
$71-75$ & 1 & 9 & 10 & 1.1 \\
TOTAL & $\mathbf{4 7 0}$ & $\mathbf{4 5 0}$ & $\mathbf{9 2 0}$ & $\mathbf{1 0 0 . 0}$ \\
\hline
\end{tabular}

\section{Ocular Complaints}

The major ocular symptoms of the welders are listed in Table 3. Similar symptoms were reported by Davies et al. (2007).

Table 2. Years of experience of the welders

\begin{tabular}{lll}
\hline Years as a welder & Frequency & Percent \\
\hline$<1$ & 2 & 0.4 \\
$1-3$ & 71 & 15.1 \\
$4-6$ & 77 & 16.3 \\
$7-10$ & 78 & 16.6 \\
$>10$ & 242 & 51.5 \\
TOTAL & $\mathbf{4 7 0}$ & $\mathbf{1 0 0 . 0}$ \\
\hline
\end{tabular}

\section{Prevalence of Ocular Conditions}

A total of $308(65.5 \%)$ welders had one or more ocular conditions while in the control group only $76(16.9 \%)$ had one or more ocular conditions. Table 4 shows the prevalence rates of the individual eye conditions diagnosed among the respondents. The commonest ocular condition among the respondents was pterygium with a prevalence of $56.6 \%$ among the welders and $6.2 \%$ in the control group. The observed prevalences are statistically significant $(p<0.05$; Chi 
$40 \quad$ Kumah et al.

Table 3. Ocular complaints reported by the respondents

\begin{tabular}{lll}
\hline Symptoms & $\begin{array}{l}\text { Welders } \\
\text { No. }(\%)\end{array}$ & $\begin{array}{l}\text { Control Group } \\
\text { No. }(\%)\end{array}$ \\
\hline Itching & $118(25.1)$ & $38(8.4)$ \\
Tearing & 263(56.0) & $14(3.1)$ \\
Floaters & $80(17.0)$ & $5(1.1)$ \\
Blur at near & $127(27.0)$ & $20(4.4)$ \\
Blur at far & $65(13.8)$ & $17(3.8)$ \\
Haloes & $11(2.3)$ & $2(0.4)$ \\
Gritty & & \\
sensation & $306(65.1)$ & $46(10.2)$ \\
Burning & & \\
sensation & $226(48.0)$ & $44(9.8)$ \\
Photophobia & $212(45.1)$ & $70(15.6)$ \\
Diplopia & $30(6.4)$ & $5(1.1)$ \\
Ocular pain & $35(7.4)$ & $6(1.3)$ \\
\hline
\end{tabular}

square test). In the study group photoconjunctivitis $(22.6 \%$.) was the second most prevalent ocular condition. From the observed prevalence rates in the two groups the work environment of the welders might be a contributory factor to the ocular conditions they suffered. For instance photokeratitis, corneal foreign bodies, corneal opacities, photoconjunctivitis and lid disorders were completely absent from the control group.

\section{Eyelid Disorders}

The study revealed that all welders were exposed to the radiations from the welding proc- esses but the damage to the eyelids was minimal. The effects of infrared and UV radiation on the eyelids ranged from mild reddening to third degree burns and, eventually, death of the skin (apoptosis). To suffer the more severe effects, the eyelid must be exposed to very high levels of infrared delivered over a short period of time, or to low levels of infrared over a long period. Infrared eyelid damage is not usually found in the industrial context (Voke, 1999b).

\section{Conjunctival Disorders}

The radiation damage to the conjunctiva was significant. Out of the total number of welders screened $396(84.3 \%)$ had pathologies on the conjunctiva and these were primarily photoconjunctivitis (106), pterygium (266) and pinguecula (24). This was as a result of the long exposure to the radiation at work. The results revealed that $74(15.7 \%)$ had normal conjunctiva.

Evidence is clear of an association between chronic UVB exposure and pterygium, a fleshy growth on the normally clear cornea. Various types of keratopathy involving deposition of altered proteins in the superficial cornea between the epithelium and Bowman's membrane, leading to opacification, have been reported by some authors (Moran and Hollows, 1984; Taylor, 1989).

A study of fishermen in Maryland, USA, found

Table 4. Prevalence rates of ocular conditions among the respondents.

\begin{tabular}{lll}
\hline Ocular Condition & $\begin{array}{l}\text { Welders }(\mathbf{N}=470) \\
\text { Frequency }(\%)\end{array}$ & $\begin{array}{l}\text { Control }(\mathbf{N}=450) \\
\text { Frequency }(\%)\end{array}$ \\
\hline Lid disorders & $2(0.4)$ & $0(0.0)$ \\
Photoconjunctivitis & $106(22.6)$ & $0(0.0)$ \\
Pterygium & $266(56.6)$ & $34(7.6)$ \\
Pinguecula & $24(5.1)$ & $12(2.7)$ \\
Photokeratitis & $15(3.2)$ & $0(0.0)$ \\
Corneal Foreign bodies & $7(1.5)$ & $0(0.0)$ \\
Corneal opacities & $4(0.9)$ & $0(0.0)$ \\
Cataract & $24(5.1)$ & $7(1.6)$ \\
Maculopathy & $19(4.0)$ & $2(0.4)$ \\
\hline
\end{tabular}


a substantially enhanced risk of both pterygium and keratopathy in individuals receiving higher exposures of UV from the sun (Taylor, 1989) but pinguecula (conjunctival lesions) were very weakly associated with UVB exposure (Taylor et al., 1989).

\section{Corneal Disorders}

The study revealed that the number of welders exposed to the radiation was high and were very susceptible to its damaging effect. Twenty six $(5.5 \%)$ welders had abnormal cornea which were mostly photokeratitis, corneal opacities and corneal foreign bodies. The remaining 444 $(94.5 \%)$ had healthy cornea.

The cornea absorbs UVC and UVB with a peak effect at $270 \mathrm{~nm}$. Studies over the last decade have indicated that exposure to UV radiation of the cornea is considerably more damaging than was previously thought. It had been known for many years that the outer epithelial layer was the region most damaged by UV radiation. Optometrists working in the USA have shown that the endothelial layer in the primate cornea is also damaged (specifically by UVB of wavelength $300 \mathrm{~nm}$ ) and this, unlike the epithelial damage, is permanent (Pitts et al., 1987).

The main response of the cornea to UV exposure is the condition called photoophthalmia, or photokeratitis, thought to be due primarily to wavelengths between $210 \mathrm{~nm}$ and $315 \mathrm{~nm}$. This is the 'welder's flash', known for over 100 years, that is experienced by arc welders who strike the arc before lowering a protective helmet. After exposure to UV, there is a latency period of approximately six to 12 hours, depending on the length and intensity of the exposure. The anterior part of the eye, the eyelids and the skin surrounding the eyes become reddened. There is some sensation of a foreign body (grittiness) and the person becomes photophobic, produces excess tears, and tightly closes both upper and lower lids (blepharospasm) to avoid pain. These acute symptoms last up to 24 hours but all discomfort disappears within about 48 hours (Ham et al.,
1982).

\section{Lens Disorders.}

The study revealed that though the welders were exposed to the radiations the damage to the lens was minimal. A total of $446(94.9 \%)$ of the welders had a clear lens while $24(5.1 \%)$ had lens opacities, affecting mainly those with long exposure, that is those above 40 years of age had immature cataract. This prevalence is higher than the prevalence of $2.5 \%$ reported by Davies et al., (2007) in a similar study in Calabar, Nigeria. In fact, $79.2 \%$ of those above 40 years had immature cataract. The results indicated that $87.5 \%$ of those with lens opacities were those who had worked over 10 years as welders. Though it had reduced their vision, it had not deteriorated to the extent that they could not work. UVB radiation is absorbed by the crystalline lens of the human eye and even some UVA (longer wavelengths) are absorbed in the older eye, into the violet end of the visible range.

The absorption of small amounts of UV daily over many years may be responsible for inducing or accelerating the formation of cataracts. There is increasing evidence implicating UV radiation as the causative factor in the production of cataracts, particularly the age-related brown or brunescent cataract occurring in the nucleus of the lens. Epidemiology indicates that the incidence of cataract is related both to the exposure to sunlight and to UV exposure for persons living at different latitudes. For instance, the incidence of cataract is increased for all age groups in Israel compared to Oxford, and in Tampa, Florida, as compared to Rochester, New York. Areas of the USA with greater sunlight duration have a higher incidence of cataract than areas with shorter duration (Voke, 1999b).

Nevertheless, the relationship between solar UV exposure and cataract is still open, as the epidemiological data cannot establish a causeand-effect relationship, and the biochemical theories are experimentally unproven. The lens 


\section{Kumah et al.}

begins absorbing UV at about 290-295nm and absorbs much of the UV spectrum up to about $375 \mathrm{~nm}$. It appears that this absorption band, centred near $365 \mathrm{~nm}$, could be the cause of UVinduced cataracts. Some studies suggest that the most effective wavelength in producing cataracts is shorter, $300 \mathrm{~nm}$, but in fact less than $5 \%$ of the $300 \mathrm{~nm}$ waveband striking the eye is transmitted by the cornea through the aqueous humour to the lens (Voke, 1999b).

\section{Retinal Disorders}

The study revealed that $19(4.0 \%)$ welders had macula problems, with $77.8 \%$ being those who had worked over 10 years. These problems were mostly age related. The remaining 451 $(96.0 \%)$ had healthy macula. The retina is mostly affected by UVA which is produced by carbide (oxy-acetylene) flame. Due to the type of radiation used which is mostly UVB and UVC produced by the electricity used in arc welding, damage to the retina and thus the macula was minimal.

\section{CONCLUSION}

Long exposure to the radiations emitted by the welding lamps at the work environment without appropriate protection by the welders might produce the ocular conditions, including pterygium, photokeratitis and cataract among others with their attendant symptoms, like gritty and burning sensations, photophobia and ocular pain. Through planned education campaigns targeted at the welders the ocular health hazards experienced by them could be minimized.

\section{ACKNOWLEDGEMENT}

We wish to express our appreciation to the Executives of the Associations of welders, mechanics and dealers in auto spare parts at Suame 'Magazine' in the Kumasi Metropolis whose members were recruited for the study. We reckon our deep appreciation to all the members who consented and took part in the study. Lastly, we are very grateful to the head of Department of Optometry and Visual Science of the Kwame Nkrumah University of Science and Technology, Kumasi for providing some logistics for the work.

\section{REFERENCES}

Cains, S. (1992). Royal Australian College of Ophthalmologists policy statement on sunglasses. MJA; 157:343-344.

Davies, K. G., Asana, U., Nku, C.O., Osim, E. E. (2007). Ocular effects of chronic exposure to welding light on Calabar welders. Nigerian Journal of Physiological Sciences 22(1-2):55-58.

Fich, M., Dahl, H., Fledelius, H. (1993). Maculopathy caused by welding arcs. A report of 3 cases. Acta Ophthalmol Copenh; 71:403-404.

Ham, W. T. Jr, Mueller, H., Ruffolo, J., Guerry, D. \& Guerry, R. (1982). Action spectrum for retinal injury from near ultraviolet radiation in the aphakic. Am. J. Opthalmol. 93: 299-300

Hollows, F., Moran, D. (1981). Cataract-the ultraviolet risk factor. Lancet; 2:1249. 1250 .

Inoue, K. (1981). Image processing for on-line detection of welding processes (Report III) - improvement of image quality by incorporation of arc. Transactions of the Japanese Welding Research Institute. 10:13-18.

Mainster, M. A., Ham, W. T., Delori, F. C. (1983). Potential retinal hazards. Ophthalmology 90:927

Moran, D. J., Hollows, F. C. (1984). Pterygium and ultraviolet radiation: a positive correlation. Br. J Ophthalmol. 68: 343-346.

Pitts, D. G., Bergmanson, J. P., Chu, L. W. F. and Waxler, M. (1987). Ultrastructural analysis of corneal exposure to UV radia -tion. Ophthalmol. (kbh) 65: 263 - 273. 
Taylor, H. R. (1981). Climatic droplet keratopathy and pterygium. Aust J Ophthalmol 9: 199 $-206$.

Taylor, H. R. (1989). Ultraviolet radiation and the eye: an epidemiologic study. Trans $A m$ Ophthalmol Soc. 87: 802-853.

Taylor, H. R, West, S., Rosenthal, F. S., Munoz, B., Newland, H.S. \& Emmett, E.A. (1989) Corneal changes associated with chronic ultraviolet radiation. Arch. Ophthlmol. 107:1481- 1484 .

Uniat, L., Olk, R. J., Hanish, S. J. ( 1986). Arc welding maculopathy. Am J Ophthalmol. 102 (3): 394-395.
Voke, J. (1999b). Radiation effects on the eye. Part 3b- Ocular effects of ultraviolet radiation. Optometry Today, July 30; 37-41.

West, S. K., Rosenthal, F. S., Bressler, N. M., Bressler, S. B., Munoz, B., Fine, S. L. and Taylor, H. R. (1989). Exposure to sunlight and other risk factors for age-related macular degeneration. Arch. Ophthalmol. 107: 875-879.

World Health Organization (2010). Ultraviolet radiation and the INTERSUN Pro-gramme: Ultraviolet radiation and health. 